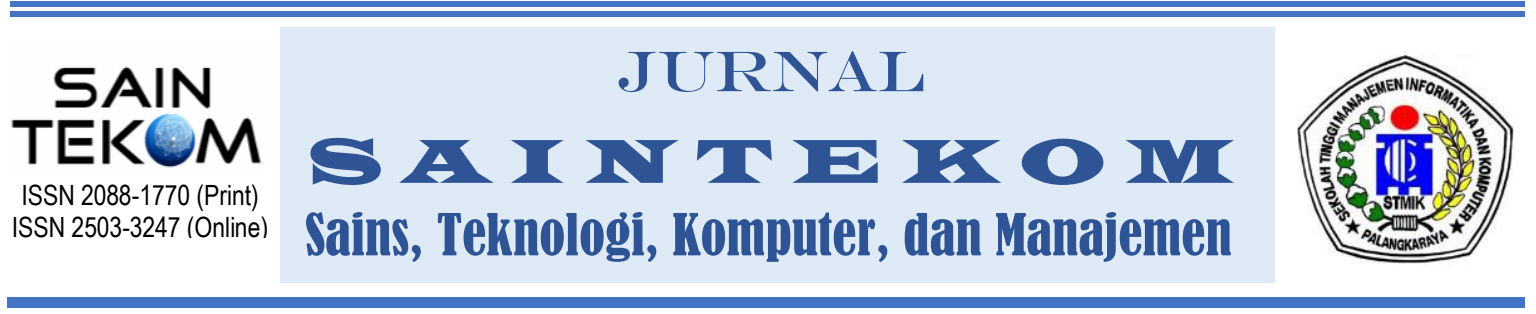

\title{
PERANCANGAN SISTEM INFORMASI KELENGKAPAN RESUME MEDIS DI RSIA HUMANA PRIMA BANDUNG
}

\author{
*Dina Mardiana Pujirahayu ${ }^{1}$, Yuda Syahidin ${ }^{2}$, Meira Hidayati ${ }^{3}$ \\ 1,2Informatika Rekam Medis \\ Politeknik Piksi Ganesha \\ Jl. Gatot Subroto No 301, Kota Bandung, Jawa Barat 40274 \\ ${ }^{3}$ Rekam Medis dan Informasi Kesehatan \\ Informatika Rekam Medis \\ Politeknik Piksi Ganesha \\ Jl. Gatot Subroto No 301, Kota Bandung, Jawa Barat 40274 \\ Email: dmpujirahayu@piksi.ac.id ${ }^{1}$, yuda.syahidin@piksi.ac.id², \\ meira.hidayati@piksi.ac.id ${ }^{3}$
}

\begin{abstract}
Completeness of filling in a medical record is very important because medical records are written evidence, especially on a medical resume sheet. Medical Resume are often used for the benefit of BPJS claims, other insurance, and currently, claims of the covid-19 patient require a complete medical resume. As the result of the research conducted there are several problems regarding the completeness of the medical resume: 1). Reporting is done manually by checking one by one paper-based medical record, 2). Report that has not been made for 2 years, 3). There are many incomplete medical resumes. This study uses a qualitative method through a descriptive, and a data collection technique used is observation. To overcome the problems that occur regarding the completeness of medical resumes at RSIA Humana Prima Bandung, the author has a solution by making a Medical Resume Complete Information System Design using Microsoft Visual Studio 2010 and Microsoft Access 2010 as database. The development method used is the waterfall method.
\end{abstract}

Keywords: Completeness, Medical Resume, Microsoft Visual Studio 2010

\section{ABSTRAK}

Kelengkapan pengisian Rekam Medis sangat penting karena rekam medis merupakan bahan bukti tertulis terutama pada lembar resume medis. Resume medis sering digunakan untuk kepentingan klaim BPJS, asuransi lain, dan saat ini klaim pasien covid-19 memerlukan resume medis yang terisi lengkap. Setelah melakukan penelitian di RSIA Humana Prima Bandung terdapat beberapa masalah mengenai kelengkapan resume medis yaitu : 1). Pelaporan yang 
masih dilakukan secara manual dengan mengecek satu persatu rekam medis berbasis kertas, 2). Pelaporan yang sudah 2 tahun tidak dibuat, 3). Ditemukan banyaknya resume medis yang tidak terisi lengkap. Penelitian ini menggunakan metode kualitatif melalui pendekatan deskriptif dan teknik pengumpulan data yang digunakan adalah observasi. Untuk mengatasi masalah yang terjadi mengenai kelengkapan resume medis di RSIA Humana Prima Bandung maka penulis mempunyai solusi dengan membuat Perancangan Sistem Informasi Kelengkapan Resume Medis dengan menggunakan Microsoft Visual Studio 2010 dan Microsoft Access 2010 sebagai database. Metode pengembangan yang digunakan adalah metode waterfall.

Kata kunci : Kelengkapan, Resume Medis, Microsoft Visual Studio 2010

\section{PENDAHULUAN}

Pada era digital ini kebanyakan dari masyarakat sudah terbiasa dengan perkembangan ilmu pengetahuan dan teknologi. Seperti sistem informasi berbasis komputer sudah menjadi kebutuhan primer bagi masyarakat untuk memperoleh informasi. Sistem Informasi berbasis komputer juga telah banyak digunakan dalam bidang kesehatan, salah satunya rumah sakit.

Rumah Sakit adalah institusi pelayanan kesehatan perorangan secara paripurna yang menyediakan pelayanan rawat inap, rawat jalan, dan gawat darurat.

$$
\text { Setiap sarana pelayanan }
$$

kesehatan wajib membuat rekam medis yang dibuat oleh dokter, tenaga kesehatan yang terkait dengan pelayanan yang diberikan. untuk menunjang penyelenggaraan pelayanan kesehatan tersebut maka setiap hasil dari berbagai pelayanan kesehatan yang diberikan rumah sakit seperti informasi medis, hasil anamnesa, pemeriksaan fisik, riwayat penyakit, diagnosa, hasil laboratorium, perjalanan penyakit dan tindakan medis lainnya dicatat kedalam suatu berkas yang disebut rekam medis (PERMENKES, 2019).

Kelengkapan pengisian pada rekam medis sangat penting dilakukan karena salah satu kegunaan rekam medis dalam aspek hukum merupakan bahan bukti tertulis. Kelengkapan dalam pengisian rekam medis dapat meringankan petugas kesehatan dalam memberikan penanganan terhadap pasien (Swari, et al., 2019). Oleh karena itu setiap rumah sakit wajib melaksanakan analisis kelengkapan berkas rekam medis, dibuat dalam bentuk laporan untuk mencapai Standar Pelayanan Minimal Rumah Sakit.

Dari hasil penelitian yang dilakukan penulis menemukan beberapa kendala mengenai kelengkapan 
pengisian rekam medis di RSIA

Humana Prima Bandung yaitu banyaknya rekam medis yang masih belum lengkap serta pelaporan yang sudah 2 tahun tidak dibuat. Sedangkan menurut Standar Pelayanan Minimal Rumah Sakit dijelaskan bahwa rekam medis harus diisi lengkap $\leq 24$ jam sesudah pelayanan selesai untuk rawat jalan dan untuk rawat inap setelah pasien dinyatakan untuk pulang. Sebelumnya penulisan laporan juga masih dilakukan dengan manual yaitu mengecek satu persatu rekam medis berbasis kertas, sehingga memungkinkan terjadinya kesalahan dalam penulisan dan perhitungan persentase laporan kelengkapan pada rekam medis. Dan ditemukan masih banyaknya rekam medis yang belum terisi lengkap terutama pada lembar resume medis seperti anamnesa, tanda tangan dokter, dan tanda tangan pasien sehingga perekam medis harus mencari dokter yang memeriksa pasien tersebut untuk melengkapi kembali rekam medis yang belum terisi lengkap.

Resume medis adalah ringkasan kegiatan pelayanan yang diberikan oleh tenaga kesehatan selama masa perawatan hingga pasien keluar dalam keadaan hidup maupun meninggal.
Dapat juga diartikan sebagai laporan pertanggung jawaban seorang dokter dalam merawat pasien, resume medis ini dibuat saat pasien pulang dari perawatan.

Kelengkapan pada lembar resume medis sangat penting untuk kebutuhan klaim BPJS atau asuransi lainnya, pada saat ini juga klaim untuk pasien covid-19 memerlukan resume medis yang sudah terisi lengkap. Untuk meningkatkan standar dalam pengisian kelengkapan rekam medis di RSIA Humana Prima Bandung perlu adanya sistem informasi berbasis komputer yang akurat, otomatis, dan cepat serta mempermudah dalam perhitungan persentase kelengkapan resume medis. Dengan adanya sistem informasi berbasis komputer perekam medis juga dimudahkan dalam pekerjaanya dan menjadi lebih efisien dalam segi waktu. Maka dari itu tujuan dari penelitian ini ialah untuk membuat Perancangan Sistem Informasi Kelengkapan Resume Medis menggunakan Microsoft Visual Studio 2010 dan Microsoft Access 2010 sebagai database.

\section{METODE}

Metodologi penelitian yaitu cara ilmiah untuk mendapatkan data yang valid yang mempunyai tujuan tertentu 
yaitu dapat ditemukan, dibuktikan, dan dikembangkan sehingga data yang diperoleh tersebut dapat digunakan untuk memahami atau memperjelas suatu masalah, memecahkan atau meminimalkan masalah serta mengantisipasi agar masalah tersebut tidak terjadi (Sugiono, 2017).

Metode Penelitian Kualitatif adalah prosedur penelitian yang memanfaatkan data deskriptif, berupa kata-kata tertulis atau lisan dari orangorang dan pelaku yang dapat diamati. Analisis data dalam metode ini dimaknai sebagai upaya mencari dan menata secara sistematis catatan hasil observasi, wawancara, dan lainnya untuk meningkatkan pemahaman tentang kasus yang diteliti.

Pada penelitian ini metode penelitian yang penulis gunakan adalah metode kualitatif melalui pendekatan deskriptif dimana metode ini bersifat deskriptif juga cenderung menggunakan analisis. Dengan memanfaatkan teori sebagai petunjuk agar fokus penelitian sesuai dengan fakta-fakta di lapangan dengan menggunakan teknik pengumpulan data observasi, kemudian melakukan perancangan sistem informasi kelengkapan resume medis menggunakan Microsoft Visual Studio
2010. Metode pengembangan pada perangkat lunak ialah kerangka kerja yang digunakan untuk merencanakan, menstrukturkan, dan mengendalikan proses pengembangan sistem informasi (Rossa \& Salahauddin, 2018). Metode pengembangan perangkat lunak yang penulis gunakan dalam penelitian ini adalah metode waterfall karena sistem informasi yang akan dibuat belum pernah dilakukan sebelumnya sehingga membutuhkan metode pengembangan perangkat lunak yang terstruktur dan cukup fleksibel untuk memperbaiki setiap kesalahan yang terjadi dalam proses perancangan sistem informasi. Metode waterfall adalah metode air terjun yang menyediakan pendekatan alur hidup perangkat lunak secara sekuensial atau terurut dimulai dari Analisa, Desain, Pengkodean, Pengujian, dan Pendukung.

Hal yang pertama dilakukan dalam perancangan sistem informasi ini adalah membuat Flowmap, Diagram context, DFD, ERD, dan tabel relasi. yang kemudian diimplementasikan kedalam design program. Berikut adalah Flowmap, Diagram context, DFD, ERD, dan tabel relasi yang dirancang dalam perancangan sistem 
informasi kelengkapan resume medis di RSIA Humana Prima Bandung.

\section{a. Flowmap}

Flowmap adalah diagram yang menunjukkan arus pekerjaan secara keseluruhan dari sistem. Diagram ini menjelaskan urutan dan prosedur yang ada di dalam sistem (Jogiyanto, 2014). Flowmap yang sedang dirancang tertera pada Gambar 1 berikut.

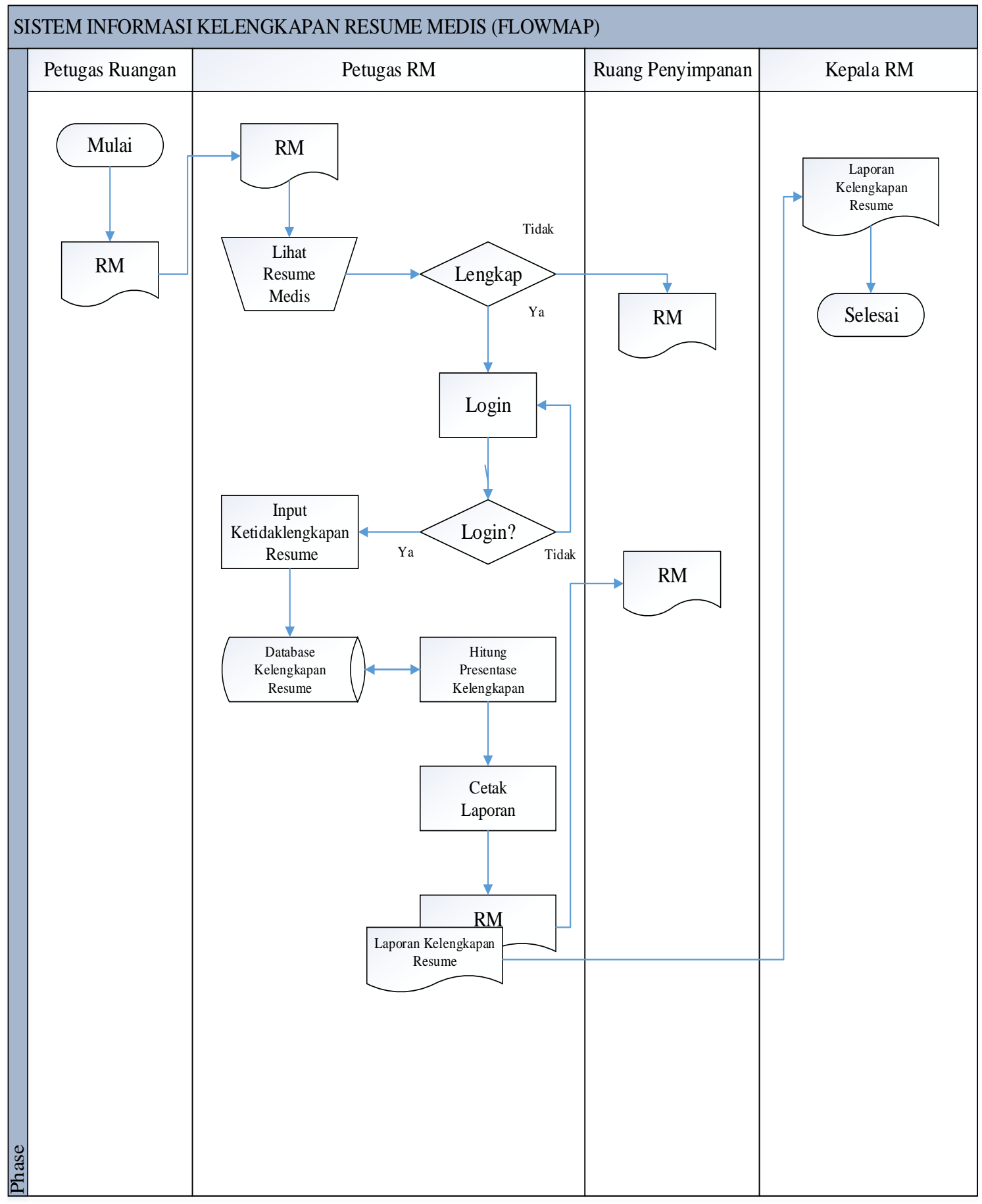

Gambar 1 Flowmap yang dirancang 


\section{b. Diagram context}

Diagram context adalah sebuah diagram sederhana yang menggambarkan hubungan antara entity luar, masukan, dan keluaran dari sistem. Diagram ini di presentasi kan dengan lingkaran tunggal yang mewakili keseluruhan sistem (Jogiyanto, 2014). Gambar 2 merupakan diagram context yang sedang dirancang.

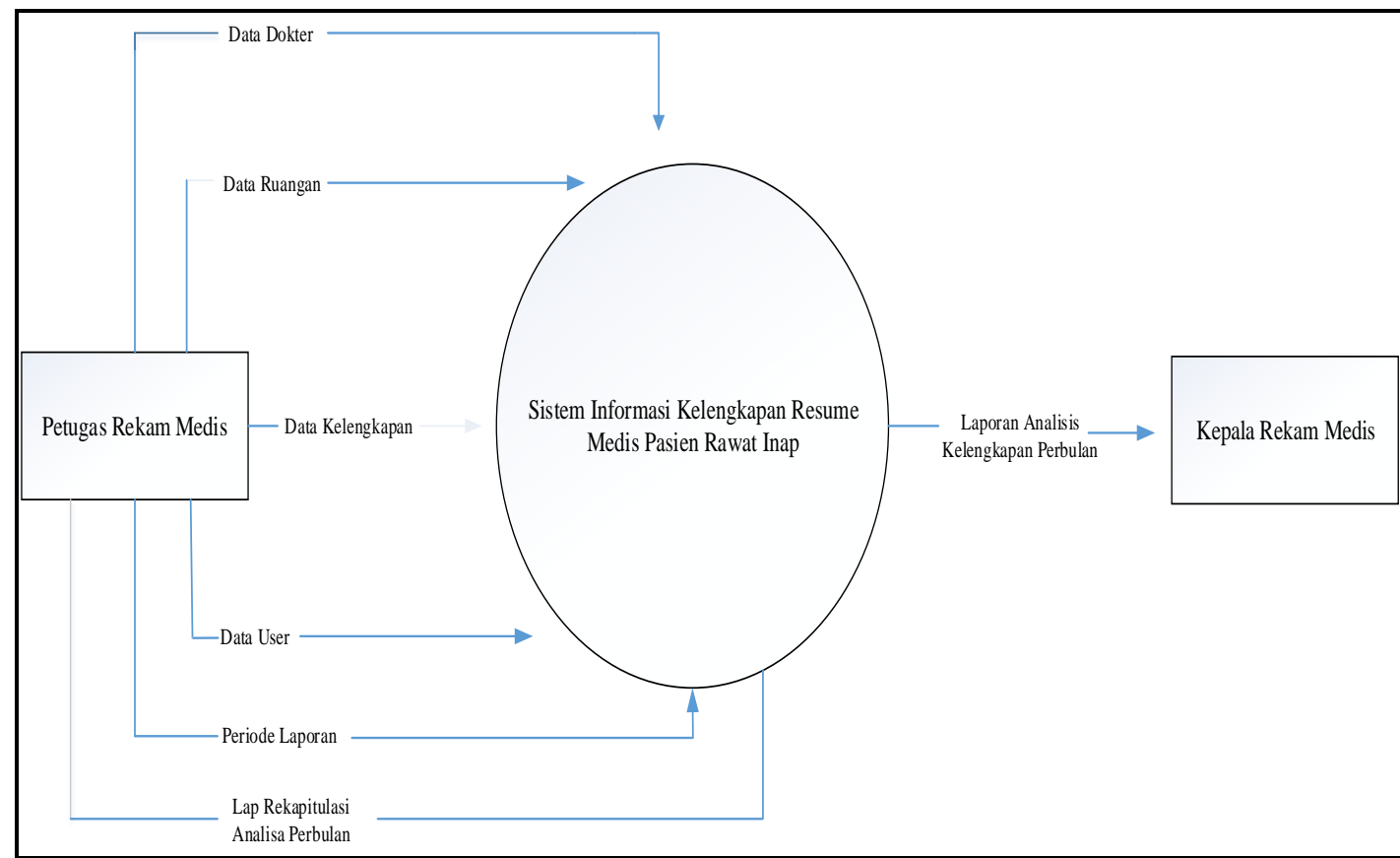

Gambar 2 Diagram Context yang dirancang

c. DFD (Data Flow Diagram)

DFD adalah sebuah model logika data atau proses yang dibuat untuk menggambarkan proses yang terjadi pada sistem, dimana data tersimpan, proses apa yang menghasilkan data tersebut, dan interaksi antara data tersimpan dengan proses yang dilakukan pada data tersebut. Gambar 3 merupakan DFD yang sedang dirancang (Andri, 2018). 


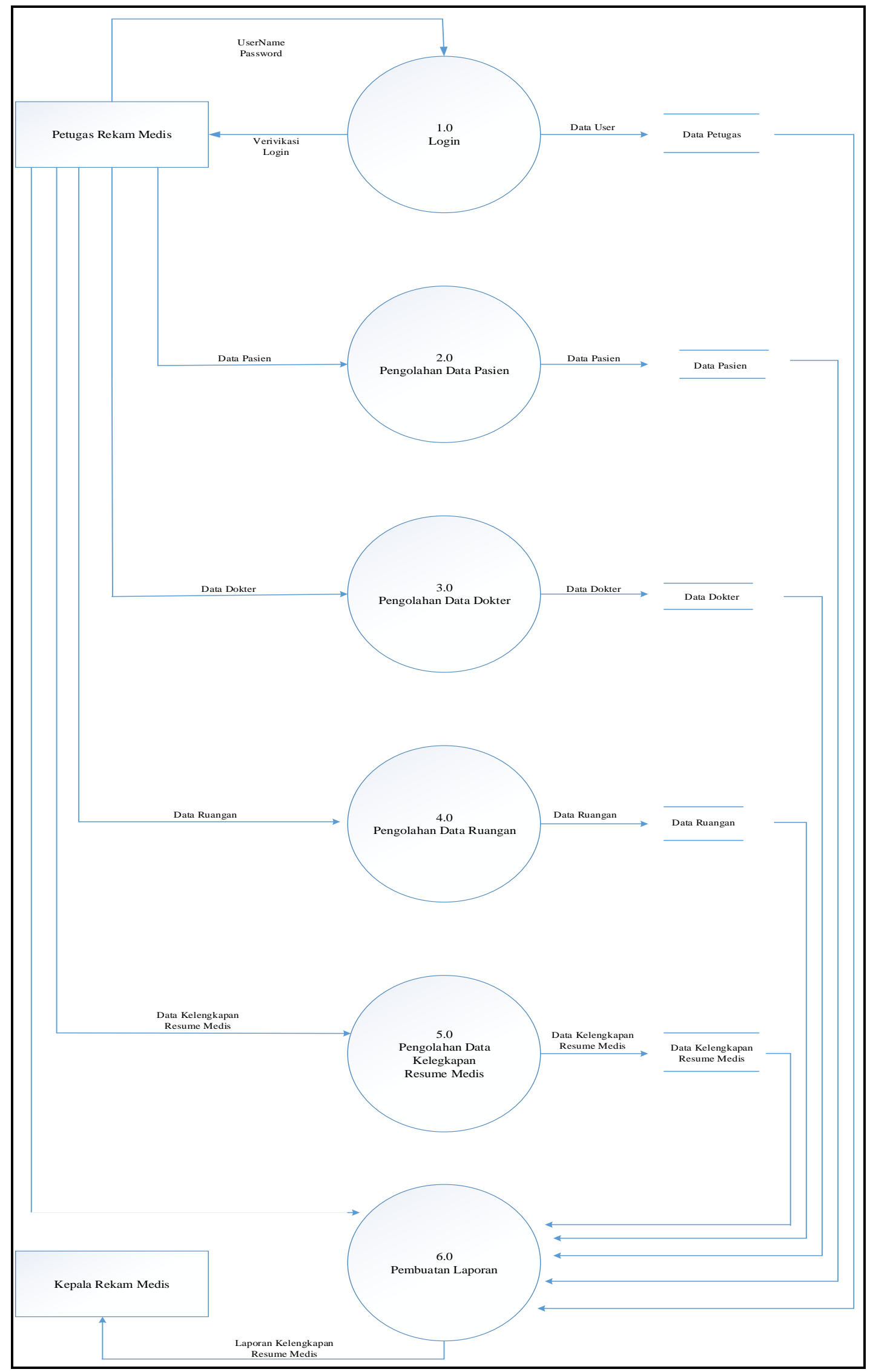

Gambar 3 DFD yang dirancang 


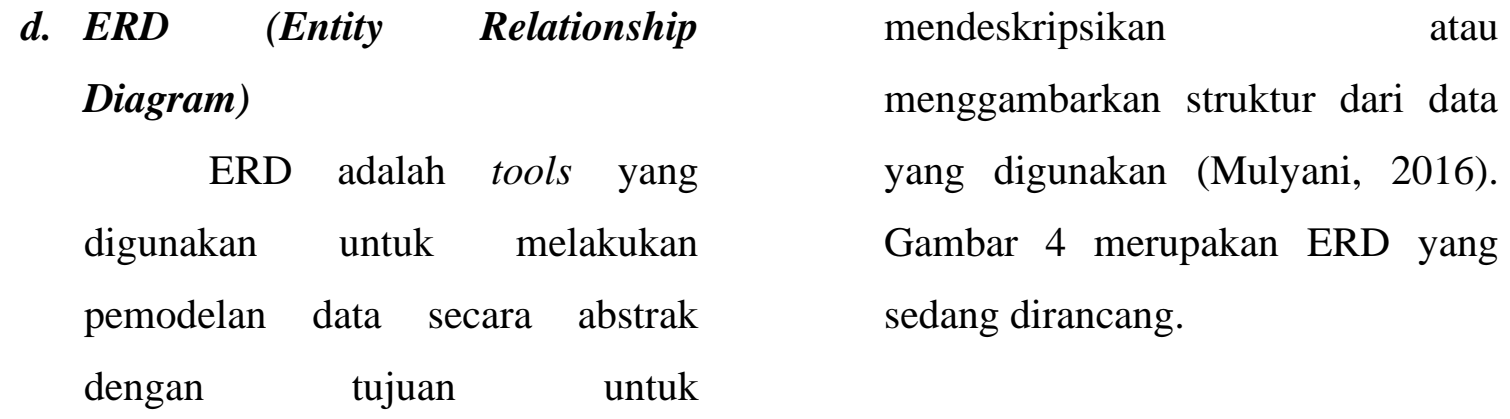

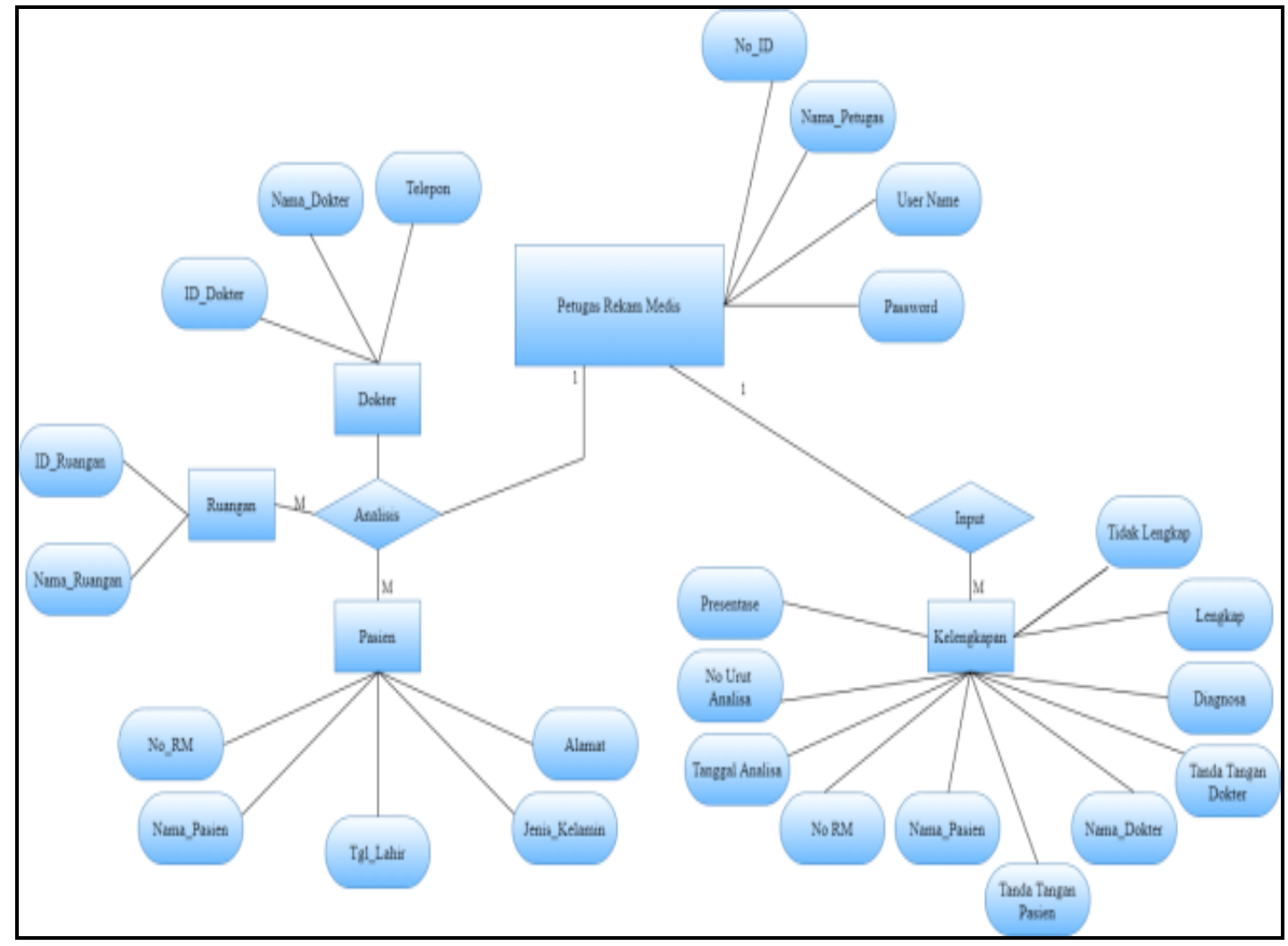

Gambar 4 ERD yang dirancang

\section{e. Tabel Relasi}

Tabel Relasi adalah hubungan antara tabel yang satu dengan yang lainnya dalam database. Hubungan antar tabel pada perancangan sistem ini tertera pada gambar 5 berikut. 


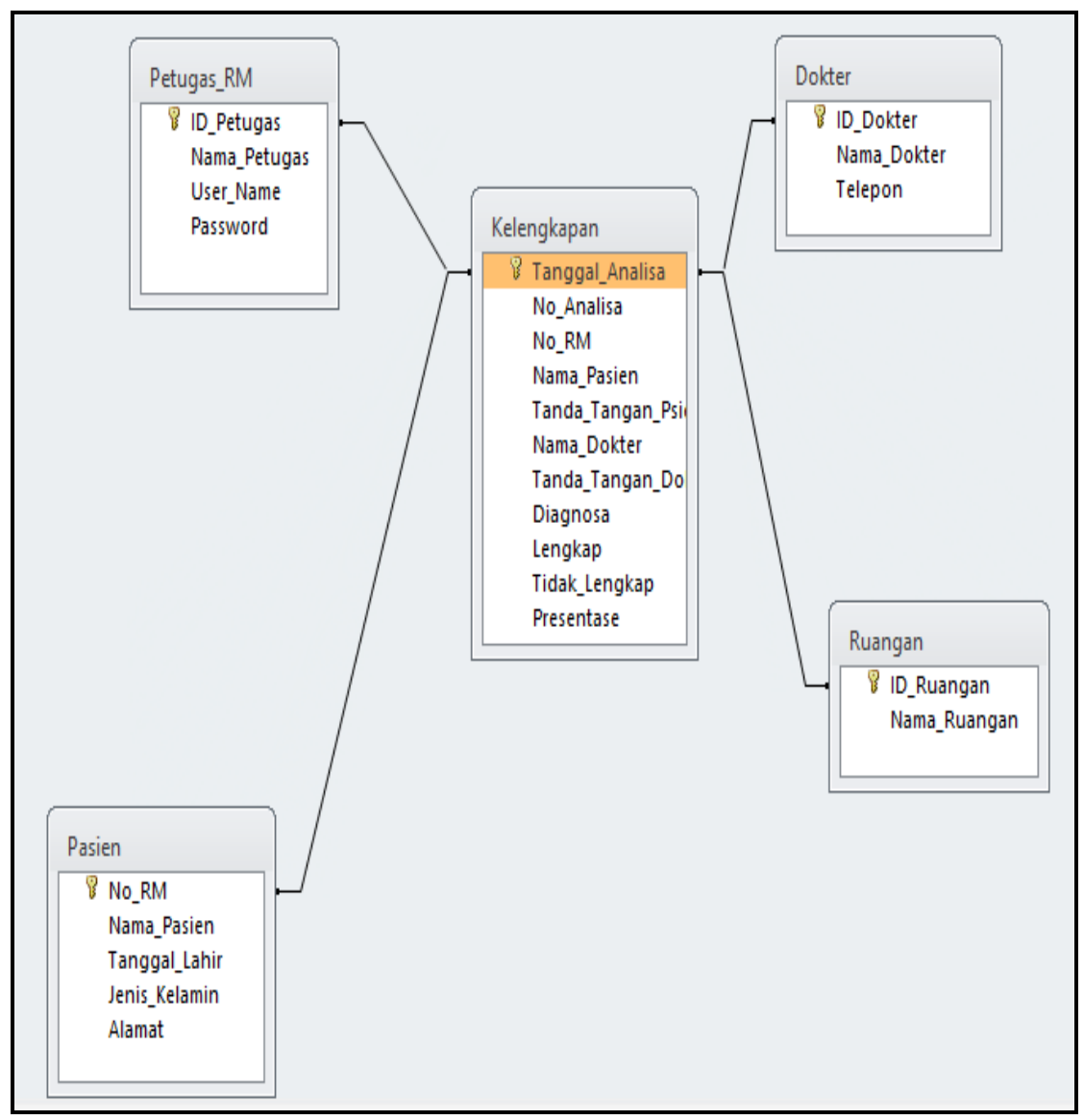

Gambar 5 Tabel Relasi yang dirancang

\section{HASIL DAN PEMBAHASAN}

\subsection{Analisis Sistem Di RSIA Humana Prima Bandung}

Saat ini belum ada Sistem Informasi yang digunakan untuk analisis kelengkapan resume medis di RSIA Humana Prima Bandung. Pencatatan laporan masih dilakukan dengan cara manual yaitu mengecek satu persatu rekam medis berbasis kertas dan menuliskan memo pada sampul rekam medis yang belum lengkap terutama pada lembar resume medis. Oleh karena itu penulis membuat Perancangan Sistem Informasi Kelengkapan Resume Medis. Sistem Informasi ini dirancang untuk memudahkan para perekam medis saat melakukan analisis kelengkapan rekam medis terutama pada lembar resume medis sehingga pengerjaan nya menjadi lebih efektif dan efisien dalam segi waktu.

Sistem Informasi

Kelengkapan Resume Medis ini dirancang menggunakan bahasa pemrograman Microsoft Visual 
Studio 2010 dan Microsoft Access sebagai Database.

\subsection{Perancangan Sistem Informasi}

$\begin{array}{lr}\text { Perancangan } & \text { Sistem } \\ \text { Informasi Kelengkapan } & \text { Resume } \\ \text { Medis ini dilakukan } & \text { untuk } \\ \text { memudahkan petugas rekam medis } & \text { pelaporan } \\ \text { dalam membuat } \quad \text { sehingga } \\ \text { kelengkapan terjadinya } \\ \text { meminimalisir sistem } \\ \text { kesalahan. Implementasi } \\ \text { merupakan kegiatan memperoleh } \\ \text { dan mengintegrasikan sumber daya } \\ \text { fisik dan konseptual yang } \\ \text { menghasilkan suatu sistem yang } \\ \text { bekerja. }\end{array}$

\section{a. Interface Program}

Interface Program ini merupakan tampilan awal yang menampilkan menu di dalam

\section{b. Design Daftar User}

Untuk daftar user perlu memasukan data-data yang tertera pada form daftar user seperti pada gambar 7 program yang dirancang. Menu yang tersedia diantaranya adalah menu login, daftar user, pengisian data dokter, pasien, ruangan, analisis kelengkapan resume medis, dan laporan yang akan dicetak. Berikut tampilan awal program yang dirancang seperti pada gambar 6.

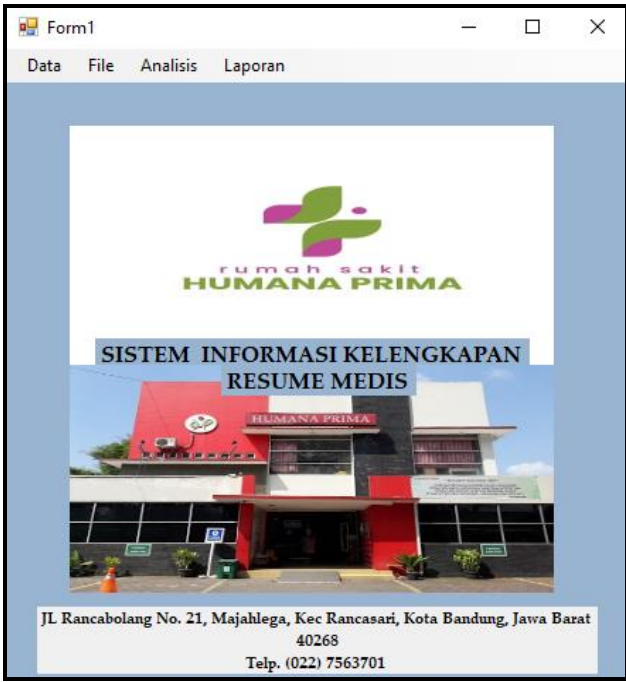

Gambar 6 Interface Program

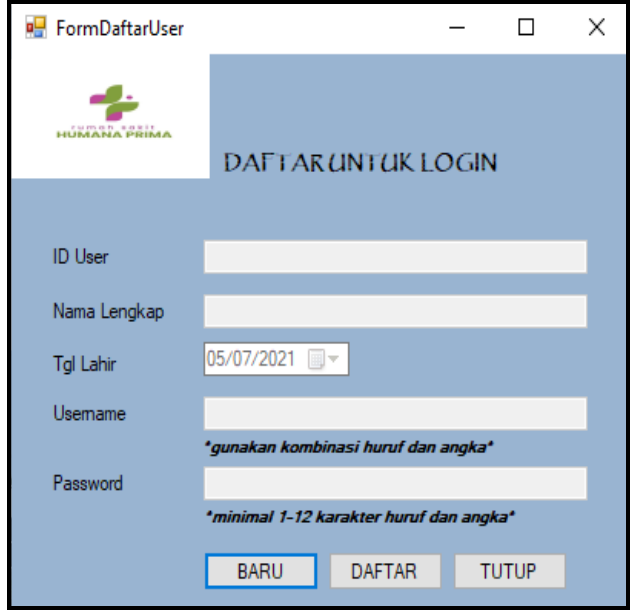

Gambar 7 Form untuk Daftar User 
c. Design Login

Login hanya dengan

memasukan username dan password yang sudah didaftarkan pada form daftar user. Gambar 8 merupakan form untuk login.

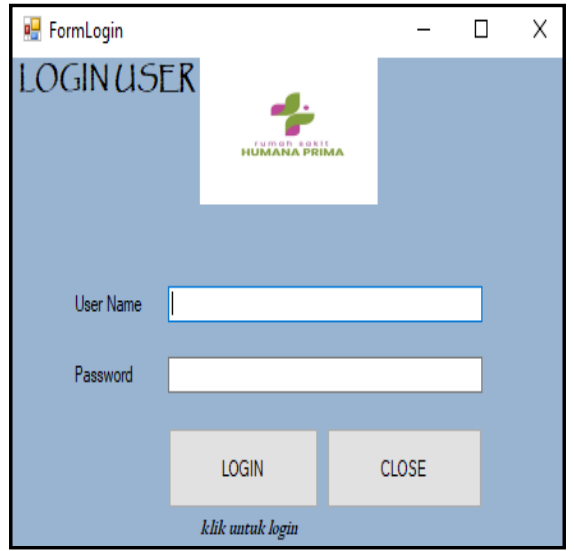

Gambar 8 Form untuk Login

\section{d. Design Analisis Kelengkapan}

\section{Resume Medis.}

Gambar 9 merupakan form untuk analisis kelengkapan Resume Medis.

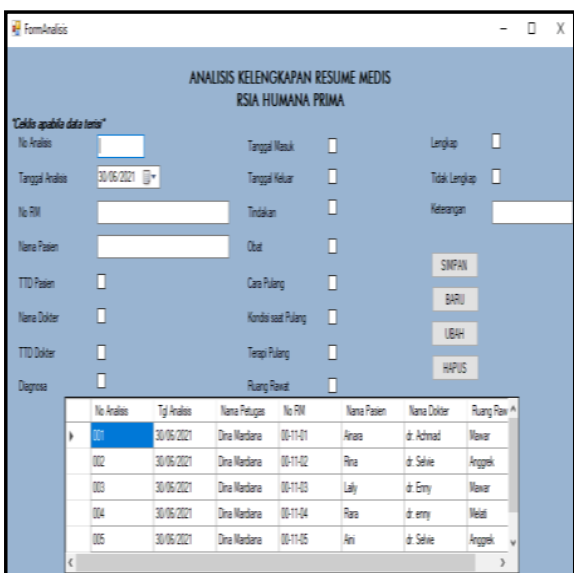

Gambar 9 Form Pengisian Analisis kelengkapan resume medis

Setelah mengisi Form analisis kelengkapan resume medis maka laporan dapat dicetak per-hari, per-bulan, dan per-periode sesuai dengan kebutuhan. Seperti pada Gambar 10 laporan dicetak per-hari, Gambar 11 Laporan dicetak per-bulan, dan pada Gambar 12 Laporan dicetak per-periode. 
e. Design Cetak Laporan Per-Hari

\begin{tabular}{|c|c|c|c|c|c|c|c|c|c|}
\hline \multirow{3}{*}{ No Analisis } & \multicolumn{9}{|c|}{$\begin{array}{l}\text { LAPORAN KELENGKAPAN RESUME MEDIS } \\
\text { RSIA HUMANA PRIMA BANDUNG } \\
\text { Majahlega, Kec. Rancasari, Kota Bandung, Jawa Barat (40286) Telp. (022) } 7563701\end{array}$} \\
\hline & \multicolumn{9}{|c|}{ Per Tanggal 17 Februari 2021} \\
\hline & Tanggal & No RM & Nama Pasien & Tgl Masuk & Tgl Keluar & Nama Dokter & $\mathrm{JL}$ & JTL & Keterangan \\
\hline 001 & $18 / 02 / 2021$ & $00-12-01$ & Aisyah & $17 / 02 / 2021$ & $17 / 02 / 2021$ & dr. Alifah & 13 & 2 & Tidak Lengkap \\
\hline 002 & $18 / 02 / 2021$ & $00-12-02$ & Gina & $17 / 02 / 2021$ & $17 / 02 / 2021$ & dr. Achmad & 12 & 3 & Tidak Lengkap \\
\hline 003 & $18 / 02 / 2021$ & $00-12-03$ & Nana & $17 / 02 / 2021$ & $17 / 02 / 2021$ & dr. Enny & 14 & 1 & Tidak Lengkap \\
\hline 004 & $18 / 02 / 2021$ & $00-12-04$ & Dede & $17 / 02 / 2021$ & $17 / 02 / 2021$ & dr. Selvie & 14 & 1 & Tidak Lengkap \\
\hline 005 & $18 / 02 / 2021$ & $00-12-05$ & Siti & $17 / 02 / 2021$ & $17 / 02 / 2021$ & dr. Enny & 15 & 0 & Lengkap \\
\hline 006 & $18 / 02 / 2021$ & $00-12-06$ & Acha & $17 / 02 / 2021$ & $17 / 02 / 2021$ & dr. Achmad & 13 & 2 & Tidak Lengkap \\
\hline 007 & $18 / 02 / 2021$ & $00-12-07$ & Seina & $17 / 02 / 2021$ & $17 / 02 / 2021$ & dr. Achmad & 15 & 0 & Lengkap \\
\hline 008 & $18 / 02 / 2021$ & $00-12-08$ & Dara & $17 / 02 / 2021$ & $17 / 02 / 2021$ & dr. Rissa & 15 & 0 & Lengkap \\
\hline 009 & $18 / 02 / 2021$ & $00-12-09$ & Oivia & $17 / 02 / 2021$ & $17 / 02 / 2021$ & dr. Rissa & 15 & 0 & Lengkap \\
\hline 010 & $18 / 02 / 2021$ & $00-12-10$ & Lela & $17 / 02 / 2021$ & $17 / 02 / 2021$ & dr. Achmad & 14 & 1 & Tidak Lengkap \\
\hline \multicolumn{6}{|c|}{ Data yang Di Analisis : 10} & Jumlah & & & $6: 10(60 \%)$ \\
\hline
\end{tabular}

Gambar 10 Design Cetak Laporan Per-Hari

\section{f. Design Cetak Laporan Per-Bulan}

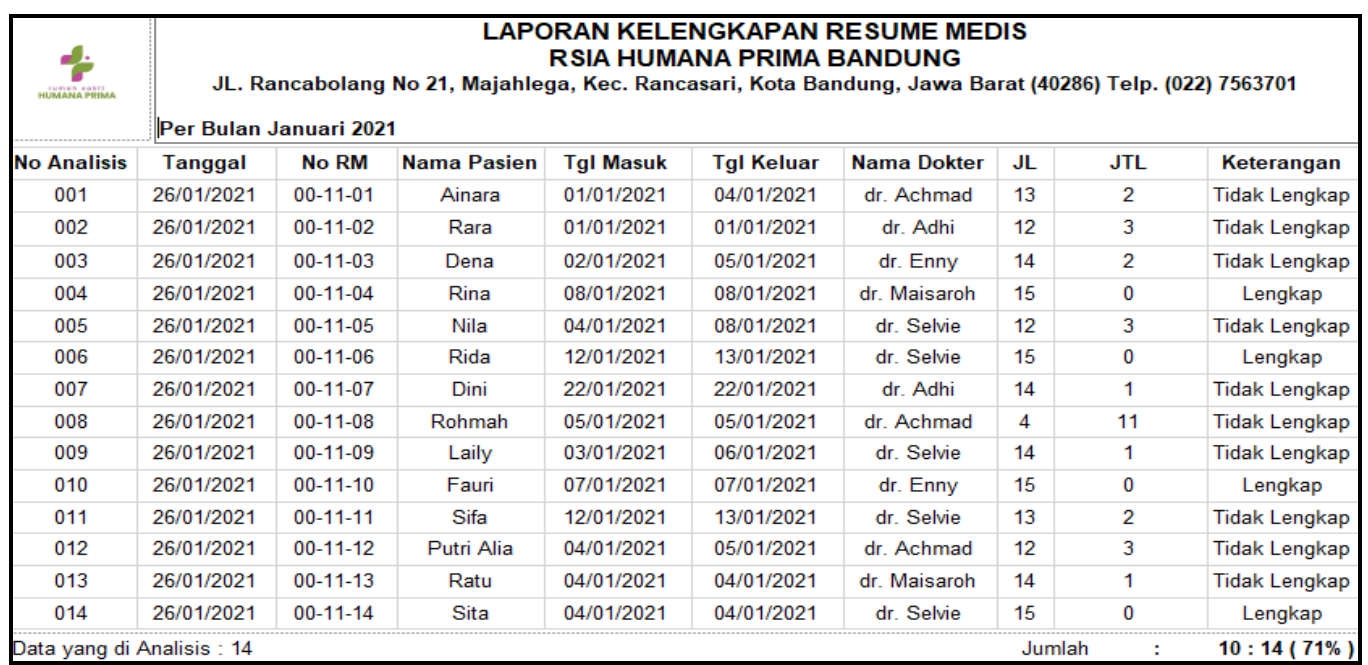

Gambar 11 Design Cetak Laporan Per-Bulan

\section{g. Design Cetak Laporan Per-Periode}

\begin{tabular}{|c|c|c|c|c|c|}
\hline 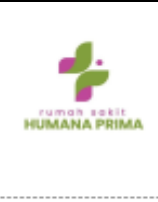 & \multicolumn{5}{|c|}{$\begin{array}{l}\text { LAPORAN KELENGKAPAN RESUME MEDIS } \\
\text { RSIA HUMANA PRIMA BANDUNG } \\
\text { JL. Rancabolang No 21, Majahlega, Kec. Rancasari, Kota Bandung, Jawa Barat } \\
\text { (40286) Telp. (022) 7563701 } \\
\text { Per Periode ( } 3 \text { bulan) Januari-Februari-Maret 2021 }\end{array}$} \\
\hline $\begin{array}{c}\text { Tanggal } \\
\text { Analisis }\end{array}$ & Bulan & $\begin{array}{c}\text { Jumlah Pasien } \\
\text { Masuk }\end{array}$ & $\begin{array}{l}\text { Resume } \\
\text { Lengkap }\end{array}$ & $\begin{array}{c}\text { Resume } \\
\text { Tidak Lengkap }\end{array}$ & Keterangan \\
\hline $20 / 02 / 2021$ & Januari & 210 & 80 & 130 & $\begin{array}{c}\text { Tidak } \\
\text { Lengkap }\end{array}$ \\
\hline $20 / 02 / 2021$ & Februari & 180 & 100 & 80 & $\begin{array}{c}\text { Tidak } \\
\text { Lengkap }\end{array}$ \\
\hline $20 / 02 / 2021$ & Maret & 227 & 110 & 117 & $\begin{array}{c}\text { Tidak } \\
\text { Lengkap }\end{array}$ \\
\hline ah yang [ & lisis : 61 & & & Imlah & $37: 617(53 \%)$ \\
\hline
\end{tabular}

Gambar 12 Design Cetak Laporan Per-Periode 


\section{SIMPULAN}

Dari penelitian yang dilakukan di RSIA Humana Prima Bandung maka ditarik kesimpulan sebagai berikut:

1. Analisis Kelengkapan Rekam Medis masih dilakukan dengan cara manual yaitu mengecek satu persatu Rekam Medis berbasis kertas dan menuliskan memo pada Rekam Medis yang belum lengkap.

2. Ditemukan masih banyaknya Rekam Medis yang belum lengkap terutama pada Resume Medis yang mempunyai peran penting kelengkapannya untuk kebutuhan klaim bpjs atau asuransi lain.

3. Penulisan Laporan Kelengkapan sudah 2 tahun tidak dibuat.

Maka dari itu penulis mempunyai saran untuk mengatasi permasalahan mengenai pelaporan kelengkapan resume medis di RSIA Humana Prima yaitu dengan membuat Perancangan Sistem Informasi Kelengkapan Resume Medis menggunakan Ms Visual Studio 2010 dan Ms Access 2010 sebagai database nya. RSIA Humana Prima juga perlu mengadakan implementasi pada sistem informasi ini sehingga petugas rekam medis dapat mengaksesnya dan pelaporan kelengkapan resume medis berjalan dengan lebih efektif dan efesien dalam segi waktu pengerjaannya.

\section{DAFTAR PUSTAKA}

Andri, K. 2018. Perancangan Sistem Informasi dan Aplikasinya. Yogyakarta: Gava Media.

Jogiyanto. 2014. Analisis dan Desain Sistem Informasi, Sistem Informasi : Pendekatan Terstruktur dan Praktisi Aplikasi Bisnis. Yogyakarta: Andi OFFSET.

Juwita Swari, S., Alfiansyah, G., Adi Wijayanti, R., \& Dwi Kurniawati, R. 2019. Analisis Kelengkapan Pengisian Berkas Rekam Medis Pasien Rawat Inap RSUP Dr. Kariadi Semarang. ARTERI : Jurnal Ilmu Kesehatan, vol.1, 5056.

Mulyani, S. 2016. Sistem Informasi Manajemen. Bandung: Abdi Sistematika.

PERMENKES. 2019. PerMenKes Republik Indonesia No.3 Th 2019 Tentang Perizinan Rumah Sakit.

Rossa, A., \& Salahauddin, M. 2018. Rekaya Perangkat Lunak Terstruktur Berorientasi Objek. Bandung: Informatika.

Sugiono. 2017. Metode Penelitian Kualitatif, Kuantitatif, dan $R \& D$. Bandung: Alfabeta CV. 